\title{
Symptom recovery after thoracic surgery: Measuring patient-reported outcomes with the MD Anderson Symptom Inventory
}

\author{
Christopher P. Fagundes, PhD, ${ }^{a}$ Qiuling Shi, PhD,${ }^{b}$ Ara A. Vaporciyan, MD, ${ }^{c}$ David C. Rice, MD,
} Keyuri U. Popat, MD, ${ }^{\mathrm{d}}$ Charles S. Cleeland, $\mathrm{PhD},{ }^{\mathrm{b}}$ and Xin Shelley Wang, MD, $\mathrm{MPH}^{\mathrm{b}}$

\begin{abstract}
Objectives: Measuring patient-reported outcomes (PROs) has become increasingly important for assessing quality of care and guiding patient management. However, PROs have yet to be integrated with traditional clinical outcomes (such as length of hospital stay), to evaluate perioperative care. This study aimed to use longitudinal PRO assessments to define the postoperative symptom recovery trajectory in patients undergoing thoracic surgery for lung cancer.
\end{abstract}

Methods: Newly diagnosed patients $(\mathrm{N}=60)$ with stage I or II non-small cell lung cancer who underwent either standard open thoracotomy or video-assisted thoracoscopic surgery lobectomy reported multiple symptoms from before surgery to 3 months after surgery, using the MD Anderson Symptom Inventory. We conducted Kaplan-Meier analyses to determine when symptoms returned to presurgical levels and to mild-severity levels during recovery.

Results: The most-severe postoperative symptoms were fatigue, pain, shortness of breath, disturbed sleep, and drowsiness. The median time to return to mild symptom severity for these 5 symptoms was shorter than the time to return to baseline severity, with fatigue taking longer. Recovery from pain occurred more quickly for patients who underwent lobectomy versus thoracotomy (8 vs 18 days, respectively; $P=.022)$. Patients who had poor preoperative performance status or comorbidities reported higher postoperative pain $($ all $P<.05)$.

Conclusions: Assessing symptoms from the patient's perspective throughout the postoperative recovery period is an effective strategy for evaluating perioperative care. This study demonstrates that the MD Anderson Symptom Inventory is a sensitive tool for detecting symptomatic recovery, with an expected relationship among surgery type, preoperative performance status, and comorbid conditions. (J Thorac Cardiovasc Surg 2015;150:613-9)

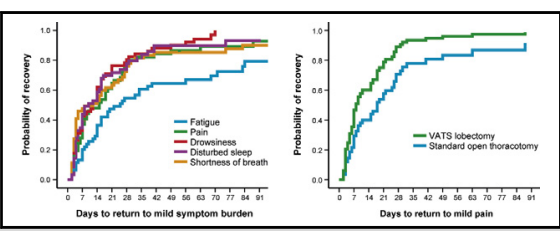

Time to recover to mild symptom severity after thoracic surgery (by symptom, surgery type)

\section{Central Message}

Using the MDASI to elicit patient-reported symptom burden is a simple, clinically relevant way to optimize care after thoracic surgery.

\section{Perspective}

We used the MD Anderson Symptom Inventory to elicit patient report of the worst symptoms experienced after thoracic surgery. Using a validated tool to gain patients' perspectives on symptom burden is a clinically relevant, user-friendly way to optimize perioperative care. Routine inclusion of symptom report to characterize recovery has the potential to improve standard practice.

See Editorial Commentary page 619

See Editorial page 461.

\footnotetext{
From the ${ }^{\mathrm{a}}$ Department of Health Disparities Research, ${ }^{\mathrm{b}}$ Department of Symptom Research, ${ }^{\mathrm{c}}$ Department of Thoracic \& Cardiovascular Surgery, and ${ }^{\mathrm{d}}$ Department of Anesthesiology \& Perioperative Medicine, The University of Texas MD Anderson Cancer Center, Houston, Tex.

This study was funded by grants from the National Cancer Institute of the National Institutes of Health, including NCI R01 CA026582 (principal investigator [PI]: Charles S. Cleeland) and the MD Anderson Cancer Center Support Grant NCI P30 CA016672 (PI: Ronald A. DePinho); and an ACS Research Scholar Grant from the American Cancer Society (PI: Charles S. Cleeland). None of the sponsors had any role in the study design, data collection, analysis, interpretation, or preparation of the report.

Received for publication Dec 9, 2014; revisions received April 6, 2015; accepted for publication May 21, 2015; available ahead of print June 16, 2015.

Address for reprints: Xin Shelley Wang, MD, MPH, Department of Symptom Research, The University of Texas MD Anderson Cancer Center, 1515 Holcombe Blvd, Unit 1450, Houston, TX 77030 (E-mail: xswang@mdanderson.org). $0022-5223 / \$ 36.00$

Copyright (c) 2015 by The American Association for Thoracic Surgery http://dx.doi.org/10.1016/j.jtcvs.2015.05.057
}

丹 Supplemental material is available online.

Patients with non-small cell lung cancer (NSCLC) who undergo major surgery experience an acute, systemic, inflammatory, neuroendocrine, and metabolic stress response related to tissue injury and the medications used during the perioperative period. This response often encompasses a cluster of nonspecific symptoms (eg, fatigue, pain, and disturbed sleep) and organ-specific symptoms (eg, shortness of breath) that together cause considerable functional impairment. In addition, up to $25 \%$ of patients who undergo 


\section{Abbreviations and Acronyms \\ $\mathrm{ERP}=$ enhanced recovery program \\ MDASI $=$ MD Anderson Symptom Inventory \\ NSCLC $=$ non-small cell lung cancer \\ PRO = patient-reported outcome \\ VATS $=$ video-assisted thoracoscopic surgery}

surgery in the United States experience postsurgical complications, ${ }^{1}$ which may exacerbate symptom severity and functional impairment, and prolong convalescence. Postoperative symptoms and their effects on functional recovery are critical determinants of patients' ability to return to planned cancer treatment, delays in which can negatively affect long-term clinical outcomes. ${ }^{2,3}$

Enhanced recovery programs (ERPs) incorporate Enhanced Recovery after Surgery ${ }^{4}$ concepts, such as multimodal opioid-sparing analgesia and minimally invasive surgical techniques. ERPs generally lead to better postoperative outcomes, which are typically quantified using objective measures (ie, decreased mortality, fewer complications, shorter hospital stays).$^{4-8}$ Missing from these metrics is the voice of the patient, who is arguably the best source of information about what "recovery" from surgery means. ${ }^{9,10}$

For example, the minimally invasive, video-assisted, thoracoscopic surgery (VATS) lobectomy is well known to be associated with fewer complications and more-rapid recovery than is standard open thoracotomy. ${ }^{11,12}$ However, to our knowledge, no empirical, patient-reported outcome (PRO) data characterize the time course and developmental trajectory of postoperative symptoms, especially during the time frame spanning from hospital discharge to return of normal functioning. ${ }^{6}$ Lack of research on how to define and measure symptomatic and functional recovery after major cancer surgery from the patents' perspective is an important gap in comprehensive postoperative care; additionally, this lack compromises any comparison of ERP innovations against standard care. , 10,13 $^{2}$

Capturing patients' perspectives on how well and how quickly they are recovering, in terms of symptom severity and persistence, functional impairment, and ability to resume planned oncology treatment, requires a validated PRO measure that is sensitive to differences related to type of surgery and variations in perioperative care. Although PROs have been widely accepted in clinical research, ${ }^{14,15}$ the use of subjective outcomes in current perioperative practice is relatively novel, despite recent recognition of their potential benefits. ' Inclusion of PROs in an ERP pathway would challenge the current paradigm of standard perioperative care and its reliance on objective metrics that do not reflect the patient perspective on the effectiveness of cancer therapy and symptom control. ${ }^{9}$
We therefore conducted a PRO-based longitudinal investigation to: (1) examine whether a validated PRO measure, the MD Anderson Symptom Inventory (MDASI), ${ }^{16}$ could be used to identify the most-severe symptoms experienced by patients with NSCLC beginning before thoracic surgery and continuing to 3 months postsurgery; (2) identify risk factors for high levels of postoperative symptoms; and (3) characterize postsurgical recovery in terms of symptom trajectories.

\section{METHODS}

\section{Patients}

We prospectively recruited newly diagnosed patients with stage I or II NSCLC who were scheduled for thoracic surgery at The University of Texas MD Anderson Cancer Center (Houston, Tex), between 2004 and 2008. Eligible patients were: aged $\geq 18$ years; naïe to any cancer treatment; able to understand English and the study requirements; and willing and able to respond to a repeated, computerized telephone interactive-voice-response-administered symptom rating scale, after they were discharged from the hospital. The study was approved by the MD Anderson Institutional Review Board. All participants gave written informed consent.

\section{Study Design and Outcome Measures}

Symptoms were assessed using the MDASI, a brief measure of the severity of 13 common, cancer-related symptoms experienced by the patient during the previous 24 hours. Each symptom is rated on an 11-point scale, with 0 being "not present," and 10 being "as bad as you can imagine." 16

Patients completed a paper and pencil version of the MDASI at the time of enrollment (presurgery baseline), and while in the hospital on days 3 and 5 after surgery. Before discharge, patients were given a demonstration of the computerized voice-response system and rehearsed using the system until they were comfortable with it. Patients were given options about which days of the week to receive calls from the system, and specified their preferred time of day for calls. Patients were called by the system 1 week after discharge, and weekly thereafter until 3 months after surgery. In addition, demographic characteristics, postoperative complications, and other clinical variables were recorded.

\section{Statistical Analysis}

All patients included in this analysis provided MDASI data at baseline and on day 3 , at a minimum. We used the average of all available scores for each symptom, to identify the 5 most-severe symptoms and construct symptom-development trajectories. Cumulative, logit, mixed-effect models were used for longitudinal analysis. Random intercepts were included in all models. In models comparing symptom scores at specific time points (day 3 , day 5 , week 1 , and month 3 after surgery) with preoperative symptom levels, we treated time as a categoric variable. In models identifying risk factors for longitudinal symptom burden, we treated time (days from surgery) as a continuous variable, with 2 segments separated by day 3 .

Age, gender, race, marital status, baseline Eastern Cooperative Oncology Group performance status, comorbid conditions, surgery type, interaction between time and surgery type, length of hospitalization, estimated blood loss, pulmonary complications, and cardiovascular complications were included in the models. SAS 9.3 (SAS Institute, Inc, Cary, NC) was used to conduct all analyses. All statistical tests were 2-sided.

We defined "postoperative recovery" as either: (1) symptom recovery to baseline level: after surgery, the patient reported 2 contiguous symptom 
levels at or below the preoperative (baseline) level (patients whose symptoms were $>3$ at baseline were excluded); or (2) symptom recovery to the mild level: after surgery, the patient reported MDASI symptom scores $\leq 3$ (none or mild) at 2 contiguous measurements. Characterizing recovery as the attainment of symptoms rated 0 to 3 on the 0 to 10 scale is based on the cutpoints used in multiple clinical practice guidelines, such as the National Comprehensive Cancer Network fatigue and pain guidelines. ${ }^{17,18}$ Empirical work has consistently demonstrated that substantial functional impairment occurs when symptoms reach moderate to severe levels. ${ }^{19,20}$ Median and mean recovery days and $95 \%$ confidence intervals (CIs) were estimated using Kaplan-Meier analysis.

\section{RESULTS}

\section{Sample}

Of the 119 patients scheduled for thoracic surgery for NSCLC who were screened for participation in the study, 42 were excluded because they did not meet inclusion criteria (34 had stage III or IV cancer; 8 had received previous treatment). Of the 77 patients enrolled, 17 did not supply baseline and day- 3 data and thus were excluded from analysis, resulting in a final sample size of 60 patients (Figure E1). Among these 60 patients, 5 completed 2 postoperative MDASI assessments; all others completed $\geq 3$ postoperative MDASI assessments. The random missing data rate was $22 \%$.

Table 1 shows baseline demographic and clinical characteristics for the sample. Approximately $48 \%$ of patients were treated with a minimally invasive surgical procedure (VATS lobectomy); no significant difference was found in the percentages of patients with stage I cancer versus stage II cancer, by type of surgery $(P=.152)$. Other than surgery type, no specific ERP-based management strategies were utilized. $^{4-8}$

\section{Major Postoperative Symptoms}

The 5 most-severe postoperative symptoms were pain, fatigue, drowsiness, shortness of breath, and disturbed sleep. Mixed modeling showed that mean fatigue peaked on day 5 after surgery, whereas the other 4 symptoms had already peaked by day 3 after surgery (the first observation point after surgery). Before surgery, approximately $13 \%$ of patients reported moderate to severe symptoms $(\geq 4$ on the 0-10 scale), the most severe of which were fatigue and disturbed sleep. At day 3 after surgery, the prevalence of moderate to severe symptoms was $51.6 \%$ for pain, $59.7 \%$ for fatigue, $54.8 \%$ for drowsiness, $33.9 \%$ for shortness of breath, and $56.5 \%$ for disturbed sleep. By 4 weeks after surgery, the only symptoms still more severe than they were at baseline were fatigue (mean: 2.92 [SD 2.45] vs 1.47 [SD 2.17], respectively; $P=.003$ ), and pain (mean: 1.55 [SD 1.97] vs 0.80 [SD 1.96], respectively; $P=.0002$ ), with the other 3 symptoms having returned to preoperative levels. By the end of month 3, all symptoms had improved to better than preoperative levels (Figure 1 and Table E1).
TABLE 1. Demographic and clinical characteristics

\begin{tabular}{|c|c|c|}
\hline Characteristic & $\mathbf{n}$ & $\%$ \\
\hline \multicolumn{3}{|l|}{ Age (y) } \\
\hline \multicolumn{3}{|l|}{ M (SD): $66.2(10.5)$} \\
\hline \multicolumn{3}{|c|}{ Median (range): 67 (32-89) } \\
\hline$<60$ & 16 & 26.7 \\
\hline$\geq 60$ & 44 & 73.3 \\
\hline \multicolumn{3}{|l|}{ Gender } \\
\hline Male & 30 & 50.0 \\
\hline Female & 30 & 50.0 \\
\hline \multicolumn{3}{|l|}{ Race } \\
\hline Non-Hispanic white & 53 & 88.3 \\
\hline Other & 7 & 11.7 \\
\hline \multicolumn{3}{|l|}{ Marital status } \\
\hline Married & 40 & 66.7 \\
\hline All others & 20 & 33.3 \\
\hline \multicolumn{3}{|l|}{ Type of surgery } \\
\hline Open thoracotomy & 31 & 51.7 \\
\hline VATS lobectomy & 29 & 48.3 \\
\hline \multicolumn{3}{|l|}{ Length of hospital stay (d) } \\
\hline \multicolumn{3}{|l|}{$\mathrm{M}(\mathrm{SD}): 6.1(3.1)$} \\
\hline \multicolumn{3}{|l|}{ Median (range): $6(2-20)$} \\
\hline$\leq 6$ & 41 & 68.3 \\
\hline$\geq 7$ & 19 & 31.7 \\
\hline \multicolumn{3}{|l|}{ Estimated blood loss (mL) } \\
\hline \multicolumn{3}{|c|}{ M (SD): $333.9(659.2)$} \\
\hline \multicolumn{3}{|c|}{ Median (range): $150(0-3450)$} \\
\hline$\leq 150$ & 34 & 56.7 \\
\hline$>150$ & 26 & 43.3 \\
\hline \multicolumn{3}{|l|}{ Preoperative ECOG PS } \\
\hline Good $(0-1)$ & 51 & 85.0 \\
\hline Poor (2-4) & 9 & 15.0 \\
\hline \multicolumn{3}{|l|}{ Pulmonary complications } \\
\hline No & 46 & 76.7 \\
\hline Yes & 14 & 23.3 \\
\hline \multicolumn{3}{|c|}{ Cardiovascular complications } \\
\hline No & 50 & 83.3 \\
\hline Yes & 10 & 16.7 \\
\hline \multicolumn{3}{|c|}{ Smoked 100 cigarettes in your lifetime } \\
\hline No & 9 & 15.0 \\
\hline Yes & 51 & 85.0 \\
\hline \multicolumn{3}{|l|}{ Comorbid conditions } \\
\hline No & 5 & 8.3 \\
\hline Yes & 55 & 91.7 \\
\hline \multicolumn{3}{|c|}{ Day-3 pain rating (scale: $0-10$ ) } \\
\hline $0-6$ & 38 & 63.3 \\
\hline $7-10$ & 22 & 36.7 \\
\hline
\end{tabular}

$\mathrm{N}=60$. VATS, Video-assisted thoracoscopic surgery; ECOG PS, Eastern Cooperative Oncology Group performance status; $M$, mean; $S D$, standard deviation.

\section{Risk Factors for Higher Levels of Postoperative Symptoms}

Mixed modeling with ordinal regression analysis was used to examine multiple factors that contributed to the development of the 5 most-severe postoperative symptoms (Table 2). Those with poorer preoperative Eastern Cooperative Oncology Group performance status 


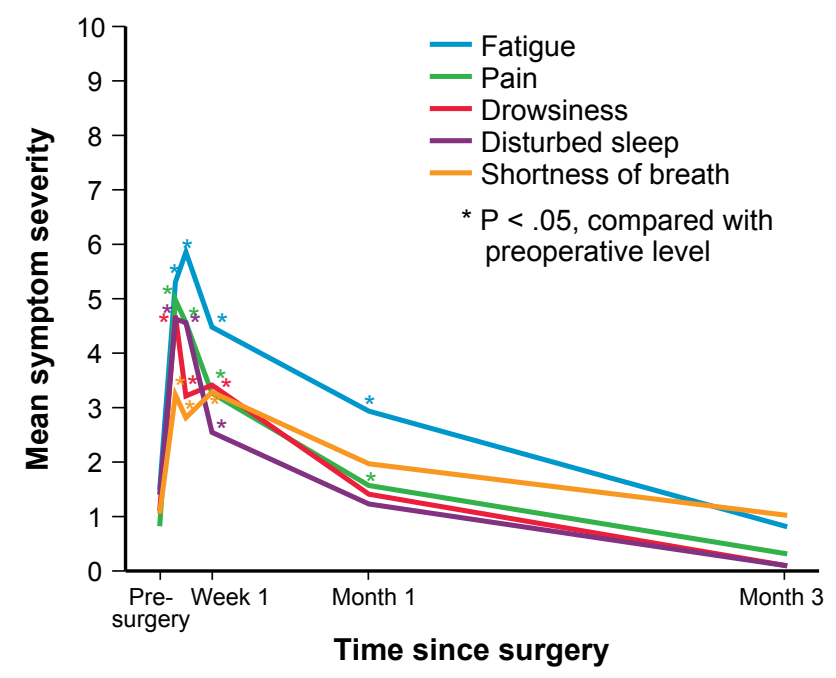

FIGURE 1. Severity levels over time for the 5 most-severe symptoms after thoracic surgery.

(2-4 vs 0-1) experienced more-severe postoperative pain $(P=.03)$. Patients who reported any comorbid condition before surgery reported higher levels of pain $(P=.04)$. Cardiovascular postoperative complications were related to a higher drowsiness score $(P=.004)$.

Significant interactions between surgery type and time were found. Compared with patients who underwent VATS lobectomy, patients who underwent standard open thoracotomy reported a more-rapid increase in the first 3 days after surgery, and a slower decrease after 3 days for 4 symptoms: fatigue, pain, drowsiness, and shortness of breath.

\section{Defining the Postoperative Recovery Time Course Using Symptom Outcomes}

Figure 2, A presents Kaplan-Meier curves of time to recover to a mild-severity level of symptoms, during the 3-month period immediately after surgery, for the 5 most-severe symptoms. Patients who underwent VATS lobectomy showed a faster recovery for pain than did patients who underwent standard open thoracotomy ( 8 days vs 18 days, $P=.022$ ) (Figure $2, B$ ). Tables E2 and E3 show additional data related to Figure 2, $A$ and $B$, respectively, on the number of patients with moderate to severe symptoms ( $\geq 4$ on the $0-10$ scale) and the probability of recovery at given time points during the study.

Table 3 presents the median time course of recovery to mild symptom ratings ( $\leq 3$ on a $0-10$ scale) by KaplanMeier analysis. Fatigue showed a slower recovery to mild severity than did the other 4 symptoms (median: 22 days vs 10-15 days). Generally, symptoms took longer to return to baseline levels than to mild symptom ratings. The median number of days for recovery to baseline symptom ratings was higher for fatigue than for the other 4 most-severe symptoms.
TABLE 2. Risk factors for higher symptom burden within 3 months of surgery, by ordinal regression analysis

\begin{tabular}{|c|c|c|c|}
\hline Symptom & Estimate* & SE & $P$ value \\
\hline \multicolumn{4}{|l|}{ Fatigue } \\
\hline Days from surgery $(\leq 3)$ & 0.23 & 0.04 & $<.0001$ \\
\hline $\begin{array}{l}\text { Surgery type by days from surgery }(\leq 3) \text {, } \\
\text { open thoracotomy vs VATS }\end{array}$ & 0.22 & 0.09 & .01 \\
\hline Days from surgery $(4-100)$ & -0.28 & 0.04 & $<.0001$ \\
\hline $\begin{array}{l}\text { Surgery type by days from surgery (4-100), } \\
\text { open thoracotomy vs VATS }\end{array}$ & -0.19 & 0.09 & .03 \\
\hline \multicolumn{4}{|l|}{ Pain } \\
\hline Days from surgery $(\leq 3)$ & 0.21 & 0.04 & $<.0001$ \\
\hline $\begin{array}{l}\text { Surgery type by days from surgery }(\leq 3) \text {, } \\
\text { open thoracotomy vs VATS }\end{array}$ & 0.44 & 0.11 & .0001 \\
\hline Days from surgery $(4-100)$ & -0.26 & 0.05 & $<.0001$ \\
\hline $\begin{array}{l}\text { Surgery type by days from surgery (4-100), } \\
\text { open thoracotomy vs VATS }\end{array}$ & -0.43 & 0.12 & .0002 \\
\hline ECOG PS 2-4 vs 0-1 at baseline & 1.14 & 0.52 & .03 \\
\hline Comorbid conditions (yes vs no) & 1.33 & 0.66 & .04 \\
\hline \multicolumn{4}{|l|}{ Drowsiness } \\
\hline Days from surgery $(\leq 3)$ & 0.14 & 0.04 & .0003 \\
\hline $\begin{array}{l}\text { Surgery type by days from surgery }(\leq 3) \text {, } \\
\text { open thoracotomy vs VATS }\end{array}$ & 0.18 & 0.08 & .03 \\
\hline Days from surgery $(4-100)$ & -0.18 & 0.04 & $<.0001$ \\
\hline $\begin{array}{l}\text { Surgery type by days from surgery (4-100), } \\
\text { open thoracotomy vs VATS }\end{array}$ & -0.17 & 0.08 & .04 \\
\hline Cardiovascular complications (yes vs no) & 1.33 & 0.46 & .004 \\
\hline \multicolumn{4}{|l|}{ Disturbed sleep } \\
\hline Days from surgery $(\leq 3)$ & 0.11 & 0.03 & .001 \\
\hline Days from surgery (4-100) & -0.14 & 0.03 & $<.0001$ \\
\hline \multicolumn{4}{|l|}{ Shortness of breath } \\
\hline Days from surgery $(\leq 3)$ & 0.27 & 0.05 & $<.0001$ \\
\hline $\begin{array}{l}\text { Surgery type by days from surgery }(\leq 3) \text {, } \\
\text { open thoracotomy vs VATS }\end{array}$ & 0.24 & 0.10 & .02 \\
\hline Days from surgery $(4-100)$ & -0.30 & 0.05 & $<.0001$ \\
\hline $\begin{array}{l}\text { Surgery type by days from surgery (4-100), } \\
\text { open thoracotomy vs VATS }\end{array}$ & -0.23 & 0.10 & .03 \\
\hline
\end{tabular}

$S E$, Standard error; VATS, video-assisted thoracoscopic surgery; ECOG PS, Eastern Cooperative Oncology Group performance status. *Multinomial logit mixed modeling: $\mathrm{N}=60,651$ observations.

\section{DISCUSSION}

The current study demonstrates the utility of the MDASI, a PRO assessment tool, for evaluating symptom severity in patients who have undergone surgery for NSCLC, and detecting expected fine differences in symptom report by type of procedure (VATS lobectomy vs standard open thoracotomy) and patient characteristics. To our knowledge, this longitudinal study is the first to use PROs to define a postoperative recovery course.

In this cohort of newly diagnosed, treatment-naïve patients with early-stage NSCLC, a cluster of symptoms peaked immediately after surgery, with one third of patients experiencing severe pain on day 3 , which was the first time symptoms were measured after surgery. Pain, fatigue, and shortness of breath were highly prevalent in the first week after surgery, representing a combined effect from surgical 

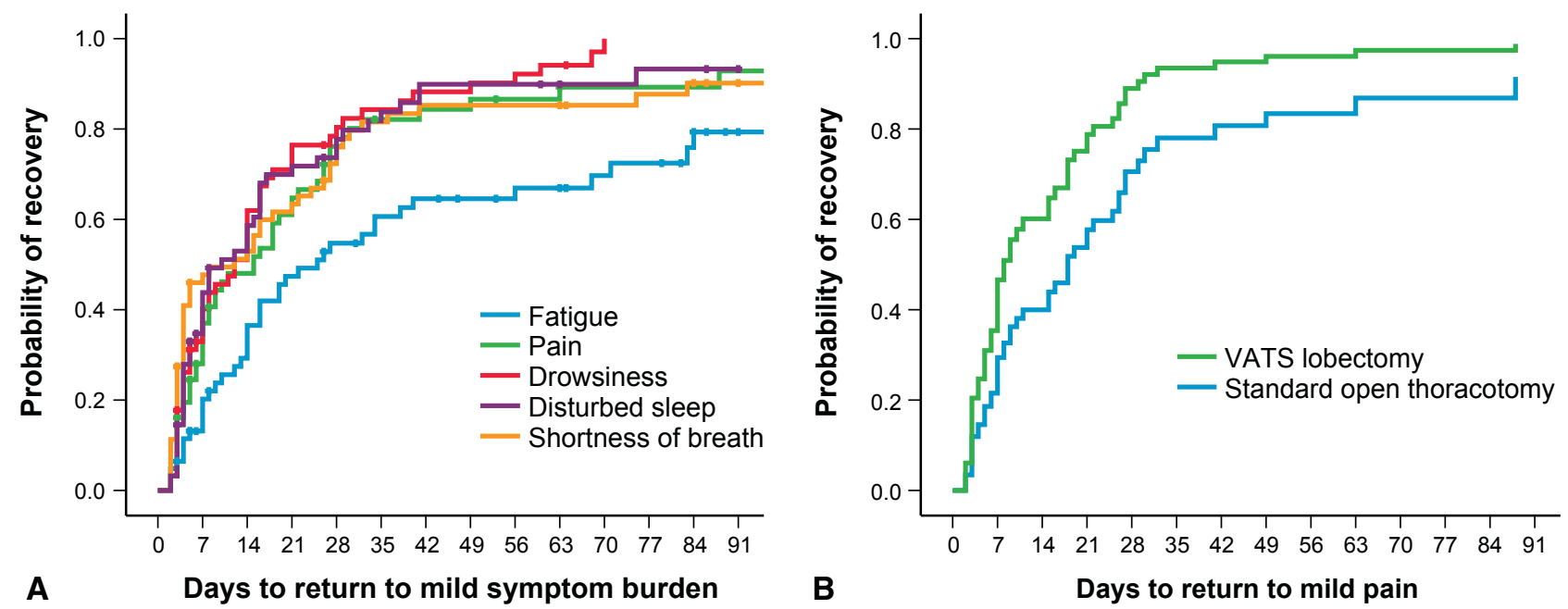

FIGURE 2. Time to symptom recovery to mild severity after thoracic surgery. A, Kaplan-Meier curves for the 5 most-severe symptoms overall. B, Kaplan-Meier curves for difference in pain recovery between standard open thoracotomy and VATS lobectomy $(P=.022)$. "Return to mild pain" was defined as a report of MDASI pain scores $\leq 3$ (none or mild) at 2 contiguous measurements. Tables E2 and E3 provide additional data related to Figure 2, $A$ and $B$, respectively, on the number of patients with moderate to severe symptoms and the probability of recovery at given time points during the study. VATS, Video-assisted thoracoscopic surgery.

insult and perioperative care. The mean ratings for most symptoms (except for fatigue) had returned to preoperative levels by the end of the first month.

Fatigue remained the most persistent symptom during the 3-month study. Postoperative fatigue had a somewhat different pattern of recovery compared with the other major symptom outcomes in this study, peaking 2 days later (at day 5) than the other symptoms (Figure 1; Table E1) and recovering more slowly. The leading role of fatigue in the postoperative setting is similar to that induced by other major cancer therapies, such as chemoradiation and stem-cell transplantation, ${ }^{21,22}$ and it reflects the fact that no effective management strategy is currently available for this symptom. Among all MDASI data collected for a total of 13 symptoms, we identified the 5 most-severe symptoms, which represent a profile of the worst symptom burden for this postsurgery patient cohort.

Our finding of differences in pain severity between VATS lobectomy and standard open thoracotomy mirrors previously reported clinical benefits from thoracoscopic lobectomy for early-stage NSCLC. ${ }^{11,23}$ This finding demonstrates that the MDASI is sufficiently sensitive to differentiate postoperative symptoms by type of procedure. The acute pain experienced by patients after open thoracotomy surgery, ${ }^{12,24}$ which is pain caused by a combination of insults such as retraction, resection, or fracture of ribs; dislocation of costovertebral joints; injury of intercostal nerves; and further irritation of the pleura by chest tubes ${ }^{25}$ is considered to be more severe than the pain produced by VATS lobectomy.

TABLE 3. Postoperative symptom recovery to mild or baseline severity, by Kaplan-Meier analysis

\begin{tabular}{lcccc}
\hline \multicolumn{1}{c}{ Symptom } & $\mathbf{n}$ & Recovered, $\mathbf{n}(\%)$ & $\begin{array}{c}\text { Median recovery time (d) } \\
(\mathbf{9 5} \% \mathbf{C I})\end{array}$ & $\begin{array}{c}\text { Mean recovery time (d) } \\
\mathbf{( 9 5} \% \mathbf{C I})\end{array}$ \\
\hline $\begin{array}{l}\text { Recovery to mild symptom severity* } \\
\text { Pain }\end{array}$ & 60 & $49(81.7)$ & $15(7-23)$ & $23(15-30)$ \\
Fatigue & 60 & $41(68.3)$ & $22(11-33)$ & $39(29-48)$ \\
Drowsiness & 60 & $53(89.3)$ & $12(7-17)$ & $18(13-23)$ \\
Shortness of breath & 60 & $51(85.0)$ & $12(2-22)$ & $22(15-29)$ \\
Disturbed sleep & 60 & $49(81.7)$ & $10(4-16)$ & $20(13-26)$ \\
Recovery to preoperative (baseline) & severity $\dagger$ & & & $56(47-65)$ \\
Pain & 60 & $35(58.3)$ & $75(61-89)$ & $62(52-72)$ \\
Fatigue & 60 & $29(48.3)$ & $27(17-37)$ & $41(32-51)$ \\
Drowsiness & 60 & $42(70.0)$ & $69(23-115)$ & $54(43-64)$ \\
Shortness of breath & 60 & $35(58.3)$ & $16(5-34)$ & $34(25-43)$ \\
Disturbed sleep & 60 & $46(76.7)$ & & \\
\hline
\end{tabular}

$C I$, Confidence interval. * "Recovery to mild severity" was defined as a report of symptom scores $\leq 3$ (none or mild, on the MDASI 0-10 scale) at 2 contiguous measurements. $\dagger$ †'Recovery to preoperative (baseline) severity" was defined as a report of MDASI symptom levels at or below the preoperative (baseline) level at 2 contiguous measurements. 
Assessing PROs allows researchers and health professionals to identify who is at greater risk for high levels of postoperative symptoms. In addition, both the Charlson Comorbidities Index ${ }^{26}$ and the American Society of Anesthesiologists physical status classification score, currently used as important routine measures of comorbidity for predicting major complications, ${ }^{27-29}$ are predictive of risk for high symptom burden from postoperative pain. This finding is in accord with prior work in other cancer populations demonstrating the detrimental impact of comorbidities on PROs. The impact of comorbidities may be additive or even synergistic - an important area for future investigation.

This work additionally defined the time course of postoperative recovery after thoracic surgery, using a PRO-based approach. The late phase of recovery has been described as the time "from hospital discharge to return to usual function and activities," 6 yet agreement is lacking in contemporary clinical practice as to how to define and measure recovery after major cancer surgery, and what constitutes optimal care during recovery. ${ }^{30}$ We defined "recovery" using a 2-pronged approach: symptom return to baseline, or symptom return to a mild severity level. Because two thirds of the patients in this study sample reported having no symptoms (rated 0 on a $0-10$ scale) at baseline, the fact that the time to return to mild symptom levels (ratings 0-3) was much shorter than that to return to baseline symptom levels is not surprising.

This study has several limitations. First, the sample was a homogenous group of patients who had early-stage lung cancer. Future studies with more diversity are warranted, to identify major symptoms and define the trajectory of postoperative recovery with more generalizability. Second, the MDASI assesses a core set of 13 symptoms that are common to patients with cancer; an MDASI version that is specifically geared to perioperative care after thoracic surgery has not yet been created, tested, or psychometrically validated.

Third, we did not collect symptom scores on days 1 and 2 after surgery, and we did not assess objective measures affecting duration of hospital stay, such as fluid status, pain medicine usage, infection, or chest drainage. The symptomatic differences between VATS lobectomy and open thoracotomy that were observed clinically may have been even more striking if these data had been included. Finally, this study occurred before our institution's ERP program was established. The recovery period, symptom profiles, and specific risk factors for impaired recovery could vary after implementation of an ERP pathway for patients undergoing various types of thoracic surgery. ${ }^{9,3}$

In sum, the current study is among the first to describe the nature of the worst symptoms reported by patients with NSCLC, during the 3 months after thoracic surgery. The establishment of an ERP pathway may be an important part of perioperative management after cancer surgery, because ERPs can be expected to provide meaningful improvements in recovery that should hasten a patient's return to planned chemotherapy or other cancer treatment when indicated. Using a straightforward, concise tool, like the MDASI, to obtain the patients' perspectives on how well they are recovering, is a clinically relevant and user-friendly method for optimizing perioperative care. ${ }^{9}$ Routine inclusion of an easy method, such as the MDASI, to characterize recovery via symptom report would be a novel PRO application in perioperative care that has the potential to improve standard practice.

\section{Conflict of Interest Statement}

The authors have nothing to disclose with regard to commercial support.

The authors appreciate Jeanie F. Woodruff, BS, ELS, for editorial assistance; as well as Ibrahima Gning, DrPH, and Winifred A. Apraku, MS, for data management.

\section{References}

1. Ghaferi AA, Birkmeyer JD, Dimick JB. Variation in hospital mortality associated with inpatient surgery. $N$ Engl J Med. 2009;361:1368-75.

2. Aloia TA, Lee JE, Vauthey JN, Abdalla EK, Wolff RA, Varadhachary GR, et al. Delayed recovery after pancreaticoduodenectomy: a major factor impairing the delivery of adjuvant therapy? J Am Coll Surg. 2007;204:347-55.

3. Aloia TA, Zimmitti G, Conrad C, Gottumukalla V, Kopetz S, Vauthey JN. Return to intended oncologic treatment (RIOT): a novel metric for evaluating the quality of oncosurgical therapy for malignancy. J Surg Oncol. 2014;110:107-14.

4. Kehlet H, Mythen M. Why is the surgical high-risk patient still at risk? $\mathrm{Br} \mathrm{J}$ Anaesth. 2011;106:289-91.

5. Varadhan KK, Neal KR, Dejong CH, Fearon KC, Ljungqvist O, Lobo DN. The enhanced recovery after surgery (ERAS) pathway for patients undergoing major elective open colorectal surgery: a meta-analysis of randomized controlled trials. Clin Nutr. 2010;29:434-40.

6. Lee L, Tran T, Mayo NE, Carli F, Feldman LS. What does it really mean to "recover" from an operation? Surgery. 2014;155:211-6.

7. Mortensen K, Nilsson M, Slim K, Schafer M, Mariette C, Braga M, et al. Consensus guidelines for enhanced recovery after gastrectomy: Enhanced Recovery After Surgery (ERAS) Society recommendations. Br J Surg. 2014;101:1209-29.

8. Cata JP, Noguera EM, Parke E, Ebrahim Z, Kurz A, Kalfas I, et al. Patient-controlled epidural analgesia (PCEA) for postoperative pain control after lumbar spine surgery. J Neurosurg Anesthesiol. 2008;20:256-60.

9. Bilimoria KY, Cella D, Butt Z. Current challenges in using patient-reported outcomes for surgical care and performance measurement: Everybody wants to hear from the patient, but are we ready to listen? JAMA Surg. 2014;149:505-6.

10. Jaklitsch MT. "How am I doing? Just ask me!" The usefulness of patient self-reported quality of life in thoracic surgery. J Thorac Cardiovasc Surg. 2015;149:663-4.

11. Stephens N, Rice D, Correa A, Hoffstetter W, Mehran R, Roth J, et al. Thoracoscopic lobectomy is associated with improved short-term and equivalent oncological outcomes compared with open lobectomy for clinical Stage I non-small-cell lung cancer: a propensity-matched analysis of 963 cases. Eur J Cardiothorac Surg. 2014;46:607-13.

12. Yan TD, Black D, Bannon PG, McCaughan BC. Systematic review and meta-analysis of randomized and nonrandomized trials on safety and efficacy of video-assisted thoracic surgery lobectomy for early-stage non-small-cell lung cancer. J Clin Oncol. 2009;27:2553-62.

13. Moloney R, Conley R, Messner D, Mitchell K, Ganesan N, Tunis S. A multi-stakeholder agenda to advance enhanced recovery for U.S. surgical patients. Available at: http://www.cmtpnet.org/docs/resources/Enhanced_ Recovery_White_Paper_9_OCT_2014.pdf. Accessed June 10, 2015.

14. Cleeland CS. Symptom burden: multiple symptoms and their impact as patientreported outcomes. J Natl Cancer Inst Monogr. 2007;37:16-21. 
15. Basch E, Abernethy AP, Mullins CD, Reeve BB, Smith ML, Coons SJ, et al. Recommendations for incorporating patient-reported outcomes into clinical comparative effectiveness research in adult oncology. J Clin Oncol. 2012;30: 4249-55.

16. Cleeland CS, Mendoza TR, Wang XS, Chou C, Harle MT, Morrissey M, et al. Assessing symptom distress in cancer patients: the M.D. Anderson Symptom Inventory. Cancer. 2000;89:1634-46.

17. National Comprehensive Cancer Network. Berger AM, Mooney K, Alvarez-Perez A, Atkinson A, Breitbart WS, Brothers B, et al. NCCN practice guidelines in oncology: cancer-related fatigue. Available at: http://williams. medicine.wisc.edu/fatigue.pdf. Accessed June 10, 2015

18. Swarm RA, Abernethy AP, Anghelescu DL, Benedetti C, Buga S, Cleeland C, et al. Adult cancer pain. J Natl Compr Canc Netw. 2013;11:992-1022.

19. Serlin RC, Mendoza TR, Nakamura Y, Edwards KR, Cleeland CS. When is cancer pain mild, moderate or severe? Grading pain severity by its interference with function. Pain. 1995;61:277-84.

20. Wang XS, Zhao F, Fisch MJ, O’Mara AM, Cella D, Mendoza TR, et al. Prevalence and characteristics of moderate to severe fatigue: a multicenter study in cancer patients and survivors. Cancer. 2014;120:425-32.

21. Wang XS, Shi Q, Williams LA, Cleeland CS, Mobley GM, Reuben JM, et al. Serum interleukin-6 predicts the development of multiple symptoms at nadir of allogeneic hematopoietic stem cell transplantation. Cancer. 2008;113:2102-9.

22. Wang XS, Shi Q, Shah N, Heijnen CJ, Cohen EN, Reuben JM, et al. Inflammatory markers and development of symptom burden in patients with multiple myeloma during autologous stem cell transplantation. Clin Cancer Res. 2014;20:1366-74.

23. Soukiasian HJ, Hong E, McKenna RJ Jr. Video-assisted thoracoscopic trisegmentectomy and left upper lobectomy provide equivalent survivals for stage IA and IB lung cancer. J Thorac Cardiovasc Surg. 2012;144:S23-6.
24. Gerner P. Postthoracotomy pain management problems. Anesthesiol Clin. 2008 26:355-67.

25. Ochroch EA, Gottschalk A. Impact of acute pain and its management for thoracic surgical patients. Thorac Surg Clin. 2005;15:105-21.

26. Charlson ME, Pompei P, Ales KL, MacKenzie CR. A new method of classifying prognostic comorbidity in longitudinal studies: development and validation. $J$ Chron Dis. 1987;40:373-83.

27. Reid BC, Alberg AJ, Klassen AC, Koch WM, Samet JM. The American Society of Anesthesiologists' class as a comorbidity index in a cohort of head and neck cancer surgical patients. Head Neck. 2001;23:985-94.

28. Froehner M, Koch R, Litz R, Heller A, Oehlschlaeger S, Wirth MP. Comparison of the American Society of Anesthesiologists Physical Status classification with the Charlson score as predictors of survival after radical prostatectomy. Urology. 2003;62:698-701.

29. Tzeng CW, Vauthey JN. Postoperative complications and oncologic outcomes after resection of colorectal liver metastases: the importance of staying on track. Ann Surg Oncol. 2013;20:2457-9.

30. Fernando HC, Landreneau RJ, Mandrekar SJ, Nichols FC, DiPetrillo TA Meyers BF, et al. Analysis of longitudinal quality-of-life data in high-risk operable patients with lung cancer: results from the ACOSOG Z4032 (Alliance) multicenter randomized trial. J Thorac Cardiovasc Surg. 2015;149:718-25; discussion, 725-26.

31. Lee BE, Korst RJ, Kletsman E, Rutledge JR. Transitioning from video-assisted thoracic surgical lobectomy to robotics for lung cancer: Are there outcomes advantages? J Thorac Cardiovasc Surg. 2014;147:724-9.

Key Words: patient-reported outcome (PRO), MDASI, postoperative care, VATS, symptoms, enhanced recovery

\section{EDITORIAL COMMENTARY}

\section{Measuring postoperative patient outcomes: Who knows best?}

Robert B. Cameron, MD

See related article on pages 613-9.

In December, 1985, a congressional mandate, Public Law 99-166, led the Veterans Health Administration to begin reporting risk-adjusted surgical outcomes in comparison with national averages - the National VA Surgical Risk Study

From the Division of Thoracic Surgery, David Geffen School of Medicine at UCLA and West Los Angeles VA Medical Center, Los Angeles, Calif.

Disclosures: Author has nothing to disclose with regard to commercial support.

Received for publication June 9, 2015; accepted for publication June 10, 2015; available ahead of print July 3, 2015

Address for reprints: Robert B. Cameron, MD, Division of Thoracic Surgery, David Geffen School of Medicine at UCLA and West Los Angeles VA Medical Center, 10780 Santa Monica Blvd, Suite 100, Los Angeles, CA 90025 (E-mail: rcameron@mednet. ucla.edu).

J Thorac Cardiovasc Surg 2015;150:619-20

0022-5223/\$36.00

Published by Elsevier Inc. on behalf of The American Association for Thoracic Surgery

http://dx.doi.org/10.1016/j.jtcvs.2015.06.017
(NVASRS). ${ }^{1}$ This project morphed into the American College of Surgeons National Surgical Quality Improvement Program (ACS NSQIP). ${ }^{2}$ Further quality measures soon emerged, including that of the Agency for Healthcare Research and Quality (AHRQ), the Surgical Care Improvement Project (SCIP) of the Joint Commission, and the Society of Thoracic Surgeons' Database Project. ${ }^{3-5}$ Quality measures quickly emerged from a jungle of possible measures, including length of stay, complication rate (morbidity); perioperative administration of antibiotics, $\beta$-blockers, and thromboembolism prophylaxis; glucose and temperature control; Foley catheter management; and others-some with very little supporting data. Enhanced Recovery Programs (ERPs) incorporating Enhanced Recovery after Surgery (ERAS) techniques were invented and tested. ${ }^{6}$ 


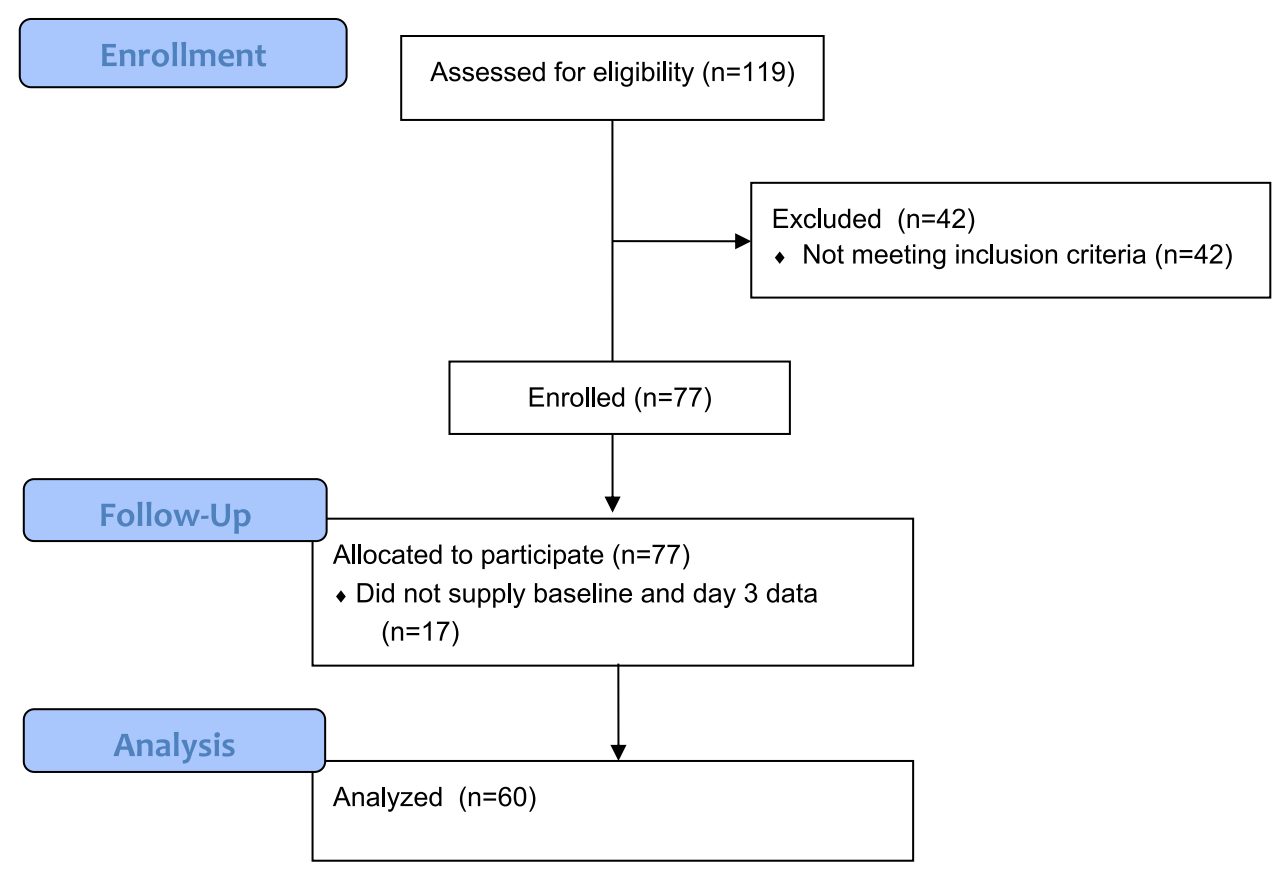

FIGURE E1. Flow of participants into the study.

TABLE E1. Most-severe symptoms related to thoracic surgery, as reported by patients on the MD Anderson Symptom Inventory

\begin{tabular}{|c|c|c|c|c|c|c|}
\hline Symptom & Before surgery $(n=60)$ & Day $3(n=60)$ & Day $5(n=20)$ & Week $1(\mathrm{n}=51)$ & Month $1(n=44)$ & Month $3(n=16)$ \\
\hline Fatigue & $1.47(2.17)$ & $5.30 *(2.90)$ & $5.85^{*}(2.76)$ & $4.47 *(2.74)$ & $2.92 \dagger(2.45)$ & $0.79(1.31)$ \\
\hline Pain & $0.80(1.96)$ & $4.97 *(3.16)$ & $4.55^{*}(2.70)$ & $3.25 *(2.84)$ & $1.55 \dagger(1.97)$ & $0.29(0.83)$ \\
\hline Drowsiness & $1.08(1.86)$ & $4.68 *(3.12)$ & $3.20 \dagger(2.65)$ & $3.40 *(2.73)$ & $1.39(1.94)$ & $0.07(0.27)$ \\
\hline Disturbed sleep & $1.38(2.19)$ & $4.62 *(3.61)$ & $4.55 *(3.28)$ & $2.53(3.08)$ & $1.21(1.68)$ & $0.07(0.27)$ \\
\hline Shortness of breath & $1.03(2.07)$ & $3.22 *(2.99)$ & $2.80 *(2.57)$ & $3.27 *(2.96)$ & $1.95(1.89)$ & $1.00(1.57)$ \\
\hline
\end{tabular}


TABLE E2. Supplemental data for Figure 2, $A$ : number of patients with moderate to severe symptoms, and probability of recovery

\begin{tabular}{|c|c|c|c|c|}
\hline \multirow[b]{2}{*}{ Symptom } & \multirow[b]{2}{*}{ Day } & \multirow{2}{*}{$\begin{array}{c}\text { n (moderate } \\
\text { to severe) }\end{array}$} & \multicolumn{2}{|c|}{ Probability of recovery } \\
\hline & & & Estimate & $95 \% \mathrm{CI}$ \\
\hline \multirow[t]{6}{*}{ Fatigue } & 0 & 60 & & \\
\hline & 7 & 49 & 0.30 & $0.18-0.42$ \\
\hline & 14 & 39 & 0.48 & $0.34-0.62$ \\
\hline & 28 & 24 & 0.61 & $0.47-0.75$ \\
\hline & 56 & 15 & 0.67 & $0.55-0.79$ \\
\hline & 84 & 7 & 0.82 & $0.68-0.96$ \\
\hline \multirow[t]{6}{*}{ Pain } & 0 & 60 & & \\
\hline & 7 & 40 & 0.48 & $0.34-0.62$ \\
\hline & 14 & 28 & 0.61 & $0.47-0.75$ \\
\hline & 28 & 12 & 0.83 & $0.73-0.93$ \\
\hline & 56 & 5 & 0.87 & $0.77-0.97$ \\
\hline & 84 & 3 & 0.95 & $0.87-1.03$ \\
\hline \multirow[t]{6}{*}{ Drowsiness } & 0 & 60 & & \\
\hline & 7 & 37 & 0.52 & $0.38-0.66$ \\
\hline & 14 & 27 & 0.71 & $0.59-0.83$ \\
\hline & 28 & 11 & 0.85 & $0.75-0.95$ \\
\hline & 56 & 5 & 0.94 & $0.88-1.00$ \\
\hline & 84 & - & - & - \\
\hline \multirow[t]{6}{*}{ Disturbed sleep } & 0 & 60 & & \\
\hline & 7 & 36 & 0.54 & $0.40-0.68$ \\
\hline & 14 & 25 & 0.70 & $0.58-0.82$ \\
\hline & 28 & 13 & 0.82 & $0.72-0.92$ \\
\hline & 56 & 5 & 0.90 & $0.82-0.98$ \\
\hline & 84 & 2 & 0.93 & $0.85-1.01$ \\
\hline \multirow[t]{6}{*}{ Shortness of breath } & 0 & 60 & & \\
\hline & 7 & 31 & 0.51 & $0.39-0.63$ \\
\hline & 14 & 28 & 0.62 & $0.50-0.74$ \\
\hline & 28 & 15 & 0.82 & $0.72-0.92$ \\
\hline & 56 & 8 & 0.85 & $0.75-0.95$ \\
\hline & 84 & 4 & 0.90 & $0.82-0.98$ \\
\hline
\end{tabular}

TABLE E3. Supplemental data for Figure 2, B: number of patients with moderate to severe pain, and probability of recovery

\begin{tabular}{lrccc}
\hline \multirow{2}{*}{ Procedure } & Day & $\begin{array}{c}\text { n (moderate } \\
\text { to severe) }\end{array}$ & \multicolumn{2}{c}{ Probability of recovery } \\
\cline { 3 - 5 } VATS & 0 & 29 & & \\
& 7 & 16 & 0.68 & $0.52-0.84$ \\
& 14 & 7 & 0.68 & $0.52-0.84$ \\
& 28 & 3 & 0.94 & $0.86-1.02$ \\
& 56 & 1 & 0.94 & $0.86-1.02$ \\
Open thoracotomy & 84 & 1 & 1.00 & $1.00-1.00$ \\
& 0 & 31 & & \\
& 7 & 22 & 0.36 & $0.22-0.50$ \\
& 14 & 19 & 0.60 & $0.46-0.74$ \\
& 28 & 8 & 0.77 & $0.64-0.90$ \\
& 56 & 3 & 0.85 & $0.74-0.96$ \\
& 84 & 1 & 0.91 & $0.81-1.01$ \\
\hline
\end{tabular}

CI, Confidence interval; VATS, video-assisted thoracoscopic surgery.

CI, Confidence interval. 